\title{
Experimental Study on the Quality of Concrete Strengthened by the Means of Infrared Thermal Imager
}

\author{
Fuchun Song, Jie Zhao, Mengchen Li \\ School of Traffic Engineering, Shenyang Jianzhu University, Shenyang, China \\ Email address: \\ Songfch@163.com (Fuchun Song), 530779841@qq.com (Jie Zhao), 891677574@qq.com (Mengchen Li)
}

\section{To cite this article:}

Fuchun Song, Jie Zhao, Mengchen Li. Experimental Study on the Quality of Concrete Strengthened by the Means of Infrared Thermal Imager. American Journal of Civil Engineering. Vol. 4, No. 2, 2016, pp. 55-60. doi: 10.11648/j.ajce.20160402.13

Received: February 26, 2016; Accepted: April 1, 2016; Published: April 7, 2016

\begin{abstract}
Testing of concrete quality of bonded steel reinforcement by the means of infrared thermal imager, study of sticky steel reinforcement concrete component under the irradiation of an external heat source surface temperature with time, spatial distribution and variation analysis internal hollowing defect thickness, size and thermal infrared imager vertical shooting angle and emission rate and other factors on the effect of infrared thermal imaging. The test results show that, the greater the thickness of internal defects, hollowing the greater area is easy to be detected. In the presence of internal defects, contrast the thickness of the site with no defect parts of the surface temperature, defect site temperature is significantly lower.
\end{abstract}

Keywords: Bonded Steel Plate, Concrete, Infrared Thermal Imaging Technology, Nondestructive Testing

\section{Introduction}

In foreign countries, many scholars have studied the infrared thermal image method in the concrete quality control of bonded steel plate reinforcement [1-2], and have achieved good results in practical engineering applications [3-5]. In China, the research of this aspect is relatively few [6-7], and the case of engineering application is not much [8-9]. From the existing research results, the infrared thermal imaging detection technology in the paste steel plate reinforced concrete structure quality judgment, mainly in the qualitative analysis stage, still lacks quantitative analysis model. In order to better promote the application of the technology in the construction, especially the steel reinforcement and detection of the bridge engineering in China with the rapid increase of highway mileage, bridge maintenance and maintenance tasks are becoming more and more difficult.

Infrared Thermal Imaging Nondestructive Testing (IRNDT) has the advantages of non-contact, fast, large measurement area, high temperature measurement resolution and no interference to the surface temperature field [10]. It has been widely used in the detection of the electrical equipment and machine equipment, the fault diagnosis of petrochemical equipment, fire detection, material internal defect detection. Single side heating method is applied to nondestructive testing of metal, alloy, plastic, ceramic and composite materials. The working principle is to measure the surface of the object by heat flux, then the surface temperature of the object is recorded by infrared thermal imaging system and infrared detector. Because of the difference in the geometrical structure and thermal physical property of the object, results in the difference of the surface temperature, so make a judgement for defects.

\section{Detection Principle of Infrared Thermal Imager}

Infrared radiation is a common phenomenon in nature. It is based on the microscopic view that any object can generate its own molecular and atomic motion without any object at room temperature. The more intense of the movement of molecules and atoms, the greater of the radiation energy is and vice versa. The surface temperature of the object is closely related to the thermal infrared energy emitted by the object. Temperature in the absolute zero of the object, will be due to their own molecular movement and radiation from the infrared. Object radiated power signal is converted into an electrical signal through the infrared detector, the output signal of the imaging device can fully faithful corresponding simulation scan the surface temperature of the space distribution, the electronic 
system, transmitted to the display, and surface heat distribution corresponding the program is obtained. Using this method, we can achieve the goal of remote thermal state imaging and temperature measurement, at the same time, the state of the object to be measured. The working principle is shown in Figure 1 [11].

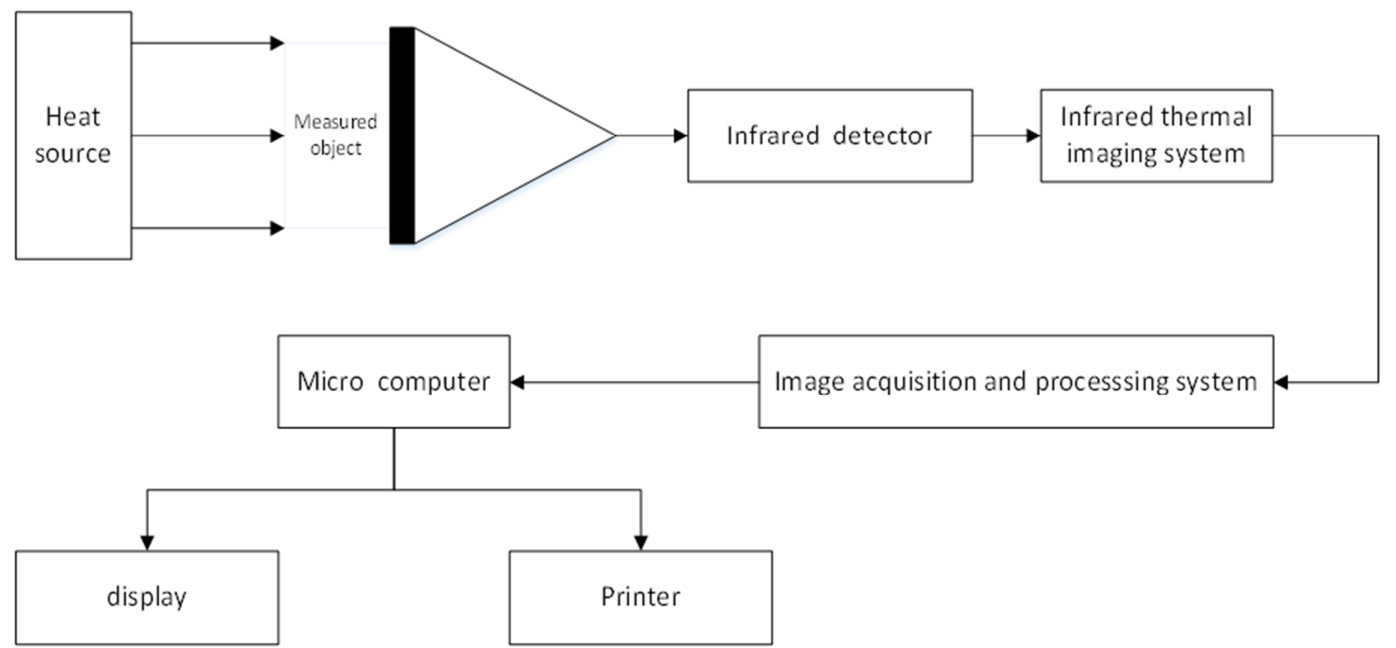

Figure 1. Sketch of infrared thermal imaging system.

Infrared thermal imaging system shows that the thermal image can reflect the thermal distribution and temperature difference of the surface of the detected object. When the internal part of the bonded steel plate is defective, the thermal conductivity of the defect site can be different with the other position due to the external heat source. Description: the thickness of the defect is $1 \mathrm{~mm}$.

\section{The Test Situation}

\subsection{Shape and Size of Specimen}

In this experiment, 2 groups of specimens were designed, with a total of 12 test pieces. The size of the specimen is as follows: $\mathrm{L} \times \mathrm{W} \times \mathrm{H}=600 \mathrm{~mm} \times 400 \mathrm{~mm} \times 300 \mathrm{~mm}$, as shown in Figure 2.

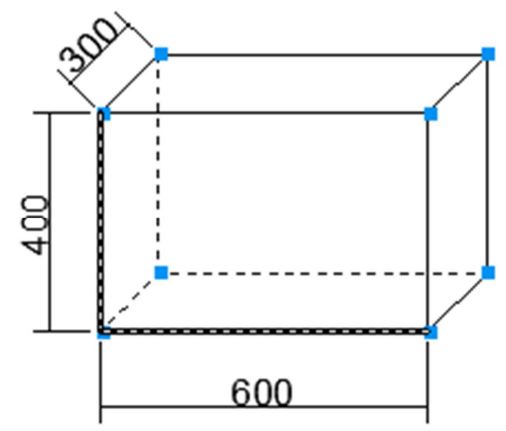

Figure 2. The specimen size.

\subsection{Specimen Processing and Design Defects}

Grouping of specimen, specimen size and defects were showed in table 1 .

After the completion of the concrete pouring, places ahead of prefabricated density for 18 Styrene board in the concrete surface the requirements of benzene plate and concrete surface flush to reserved defects of concrete normal curing 28 days after, dismantling, removing the hard surface of Styrene board in. The production of the defects were showed in Figure 3.

Table 1. Grouping design.

\begin{tabular}{|llll|ll}
\hline Group & NO. & $\begin{array}{l}\text { Size } \\
(\mathbf{H} \times \mathbf{W} \times \mathbf{L} \\
\mathbf{m m})\end{array}$ & $\begin{array}{l}\text { Defect } \\
\text { type }\end{array}$ & $\begin{array}{l}\text { Defect size } \\
(\mathbf{L} \text { or } \mathbf{R ~ m m})\end{array}$ & $\begin{array}{l}\text { Defect } \\
\text { thickness } \\
(\mathbf{m m})\end{array}$ \\
\hline $\begin{array}{l}\text { TIS1-A } \\
\text { TIS1-B }\end{array}$ & 2 & $300 \times 400 \times 600$ & Square & $15 / 10 / 6 / 4 / 2$ & 1 \\
\hline $\begin{array}{l}\text { TIS2-A } \\
\text { TIS2-B }\end{array}$ & 2 & $300 \times 400 \times 600$ & Square & $15 / 10 / 6 / 4 / 2$ & 2 \\
\hline $\begin{array}{l}\text { TIS3-A } \\
\text { TIS3-B }\end{array}$ & 2 & $300 \times 400 \times 600$ & Square & $15 / 10 / 6 / 4 / 2$ & 3 \\
\hline $\begin{array}{l}\text { TIS4-A } \\
\text { TIS4-B }\end{array}$ & 2 & $300 \times 400 \times 600$ & Round & $15 / 10 / 6 / 4 / 2$ & 1 \\
\hline $\begin{array}{l}\text { TIS5-A } \\
\text { TIS5-B }\end{array}$ & 2 & $300 \times 400 \times 600$ & Round & $15 / 10 / 6 / 4 / 2$ & 2 \\
\hline $\begin{array}{l}\text { TIS6-A } \\
\text { TIS6-B }\end{array}$ & 2 & $300 \times 400 \times 600$ & Round & $15 / 10 / 6 / 4 / 2$ & 3 \\
\hline
\end{tabular}

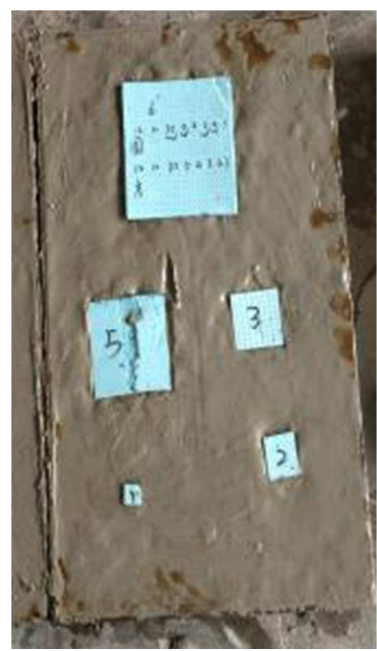

Figure 3. Specimen making. 


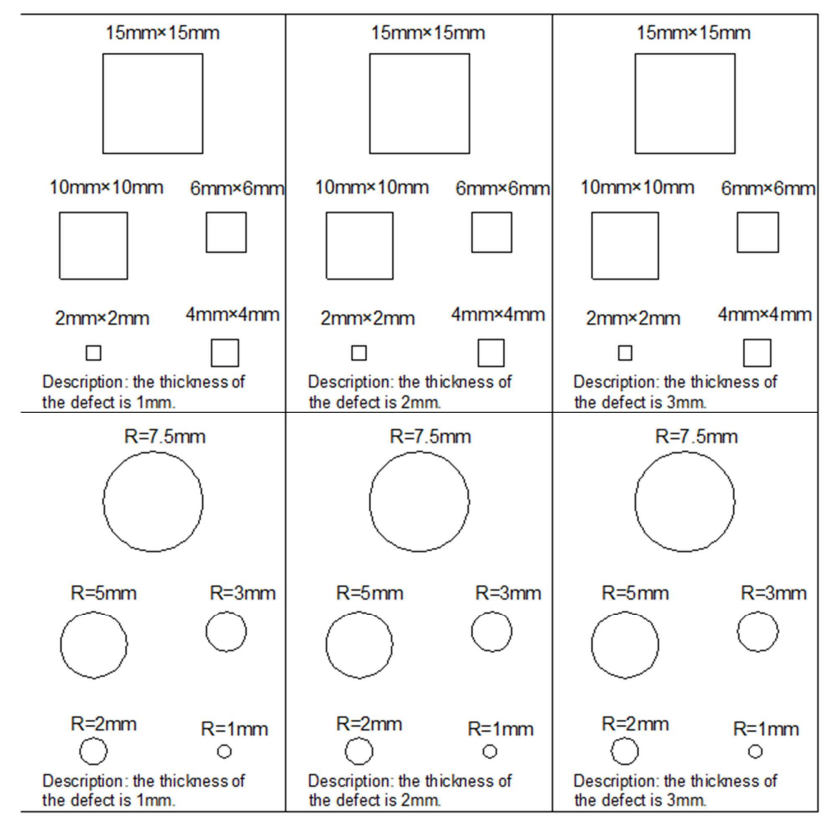

Figure 4. Sketch of hollowing distribution ( $\mathrm{mm})$. air, so density hollowing material selection and heat transfer of air performance similar to 8 styrene foam board. The distribution of the defects in each group is showed in Figure 4.

\subsection{Strengthening by Gluing Steels}

Test using SKO epoxy adhesive, test the steel steps:

(1) the test was carried out by using $6 \mathrm{~mm}$ steel plate. Steel plate bonding surface with a flat grinding wheel burnish derusting, until metal luster, and then the structural adhesive coated on the plate teach the bonding surface and the plate central position smear glue of a thickness of $3 \mathrm{~mm}$, both sides can be thinne r [12-15]. (2) with blade closely, uniformly were applied in surface cleaning concrete joint surface and plate combined with surface to fully-immerse in the glue on the surface. (3) in order to prevent the plate from sliding on the concrete surface, some fixed measures should be taken, and a certain load is applied to the steel plate to make the structural adhesive on the steel plate and the concrete surface.

Due to the practical engineering, hollowing media mainly is
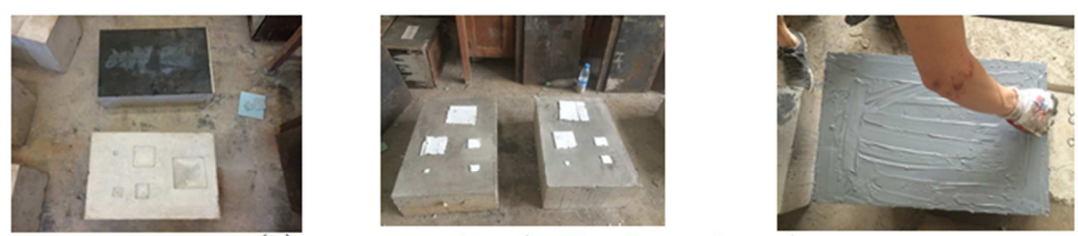

(a) release

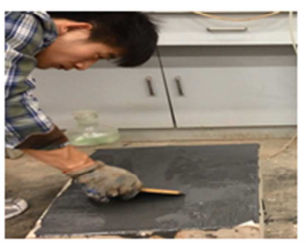

(d) concrete surface brush glue

(b) reservation hollowing place foamed polystyrene board

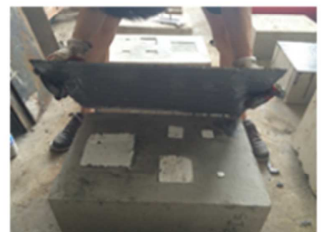

(e) with bonding steel plates (c) plate brush glue

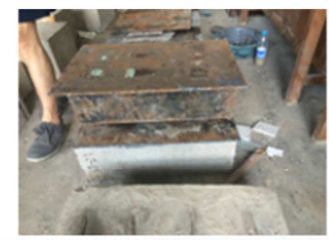

(f) fixed loading

Figure 5. Reinforcement test piece defect production process.

Test pieces of the production process: (a) release, (b) reservation hollowing placed foamed polystyrene board, (c) plate brush glue, (d) concrete surface brush glue, (E) with bonding steel plates, (f) fixed loading. As shown in Figure 5.

\subsection{Experimental Apparatus and Test Method}

Experiment instrument for R1 FlukeTi infrared thermal image instrument for measuring temperature range: $-20^{\circ} \mathrm{C}$ to $250^{\circ} \mathrm{C}$, precision: $\pm 0.1^{\circ} \mathrm{C}$ ) handheld in detected paste plate specimen before, adjust the distance, angle and focal length, to the imaging effect best as the standard, while the use of thermometer measuring accident surface temperature. On the specimen surface of continuous observation, every 10 minutes to paste plate filming an infrared thermography and record temperature inspecting instrument on the corresponding readings; indoor heating device for electric heating fan (power of $1200 \mathrm{~W}$ to $2000 \mathrm{~W}$ ). Test apparatus and equipment are as shown in Figure 6.
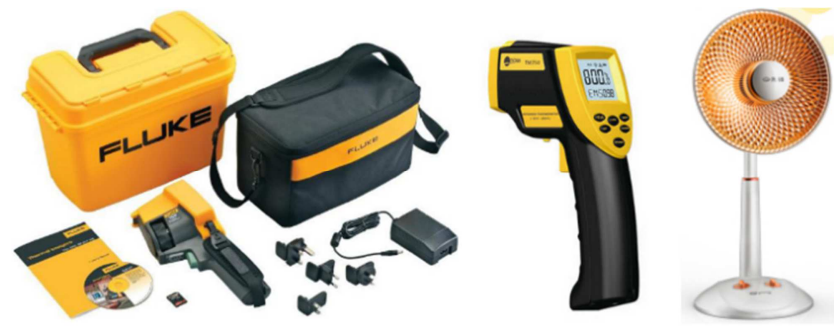

(a) Thethermalimager (b) Thermodetector (c) The heater

Figure 6. Test equipment.

Because of the structure of the glued steel specimen is not hot, it is required to apply the active heating to the surface of the steel plate. At present, some scholars have carried out a 
special research on the method. Usually can be used for high-power infrared led to an external heating source, there are also some scholars by surface cooling method, this principle and the heating is the same, by heat transfer from the plate surface temperature difference is formed [16-19]. Whether the method of heating or cooling, to ensure that the uniformity of heat transfer is essential, this experiment in the indoor heating, so that the heating of the test piece surface of the test piece is heated, the test piece is heated to a certain temperature, the use of cooling method to test pieces of testing.

\section{Experimental Results and Analysis}

\subsection{Thermal Imaging Results}

At normal temperature, the TIS1-A is tested, and the results were showed in Figure 7. It can be seen from the figure, normal temperature test edge higher temperature on the other region, the main reason is due to the specimen edges paste without full that hollowing and due to the specimen edges with the surrounding air contact heating temperature is slightly higher. Thus it can be seen that the measured is the ambient temperature which also has certain influence on the specimen, but the main effect of specimen edge position.

The test was conducted in September, the indoor temperature is about $20^{\circ} \mathrm{C}$, the test uses the indoor cooling method, first of all,the test pieces of heating, when the temperature of the surface of the specimen is about $80^{\circ} \mathrm{C}$, the time is about 50 minutes, and then stop external heating; the test results are not obvious in the $80^{\circ} \mathrm{C}$ to $60^{\circ} \mathrm{C}$ range of the test results, when the temperature drops to about $50^{\circ} \mathrm{C}$ to $30^{\circ} \mathrm{C}$, the temperature difference between the steel defect area and the non-defect area is beginning to appear.

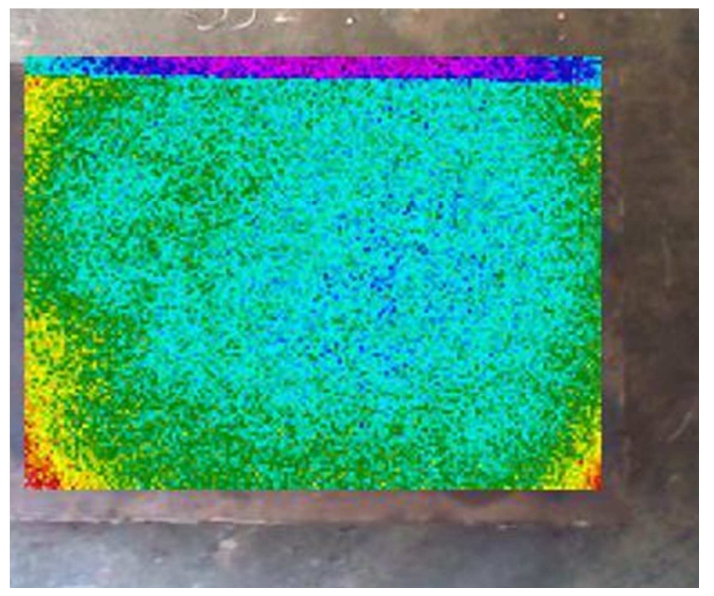

Figure 7. Steel plate surface temperature infrared thermal image map pasting.

In this experiment, the cooling method used to test the temperature is not easy to control, and the operation process is complicated. In order to measure the effect of temperature, the temperature of the sample is measured. The average temperature of the specimen TIS1-A is shown in Figure 8.

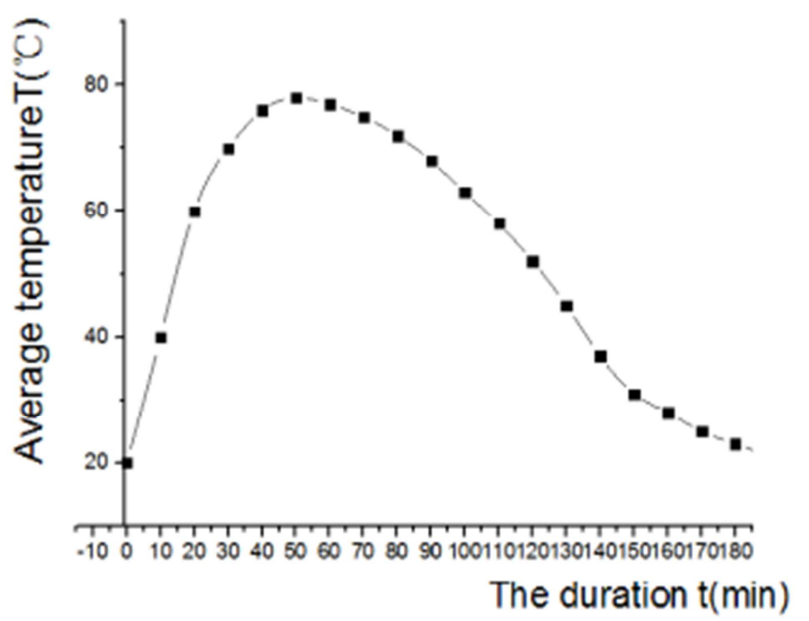

Figure 8. Variation of surface mean temperature field with time.

\subsection{Analysis of Factors Affecting Thermal Images}

\subsubsection{The Internal Defect Size}

In this experiment, 5 defects were detected by thermal imaging, which can be detected by thermal imaging, which can be detected in 4 . From a large number of thermal imaging analysis results we can see that the same size of the internal defects, the greater the thickness of the surface temperature is higher. This is mainly due to the greater the heat capacity of large area and thickness of hollowing and the cold zone effect more obvious; when the ambient temperature tends to be constant and paste steel plate and concrete specimen reached thermal equilibrium, hollowing part of surface temperature and no hollowing part of the surface temperature did not differ. At the same time cannot detected by infrared thermography to judge hollowing exists. In this test, the test pieces are uniformly reduced to $50^{\circ} \mathrm{C}$ to $30^{\circ} \mathrm{C}$ (need to define the optimum temperature range of the test environment). The test results are good, and the infrared thermal image is shown in Figure 9. Thus, the larger the area, the greater the thickness of the internal defects can be detected.

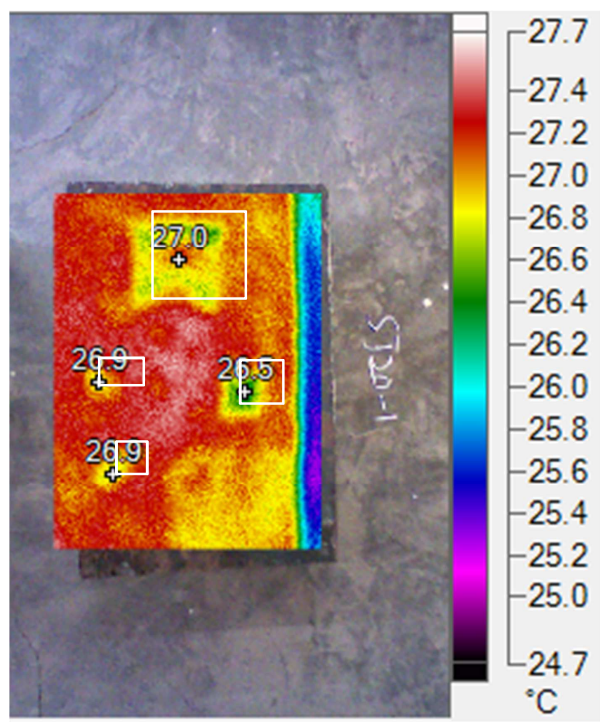




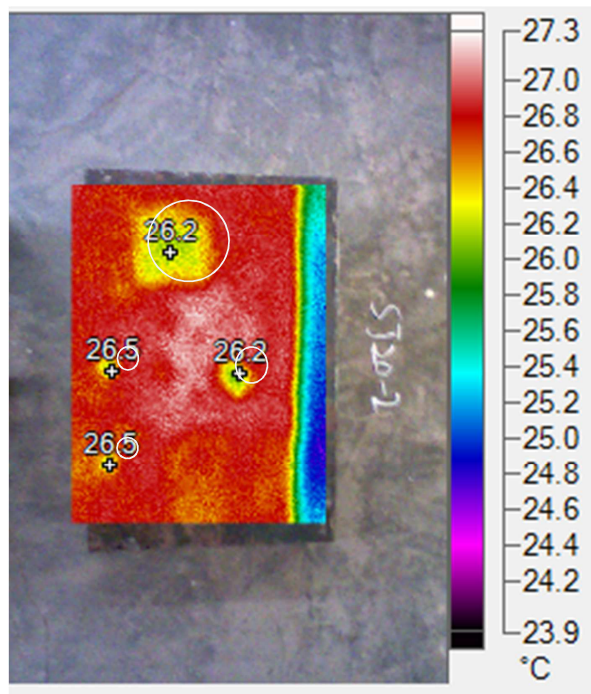

Figure 9. The infrared thermal image.

\subsubsection{The Size and Thickness of Defects}

The infrared thermal images of different sizes and thicknesses were analyzed, and the surface temperature was extracted. Analysis shows that the hollowing part of the infrared image surface is low temperature zone; instead, no hollowing part of the surface is relatively high temperature region, which is mainly due to the large defects of the dissipation of heat faster, and small defects of the local heat accumulation and dissipation slower. According to the imaging image, the position, shape and size of the defect can be estimated, and the approximate area of the defect can be estimated by using the ratio of the differential calculus. When the thickness of the defect is $3 \mathrm{~mm}$, the imaging effect is better than that of $1 \mathrm{~mm}$ and $2 \mathrm{~mm}$. At the same time, the effect of thermal imaging is not obvious when the defect area is small (less than $4 \mathrm{~mm} 2$ ). Thus, infrared thermography on the detection effect of the internal defects of the larger and thicker hollowing is more obvious.
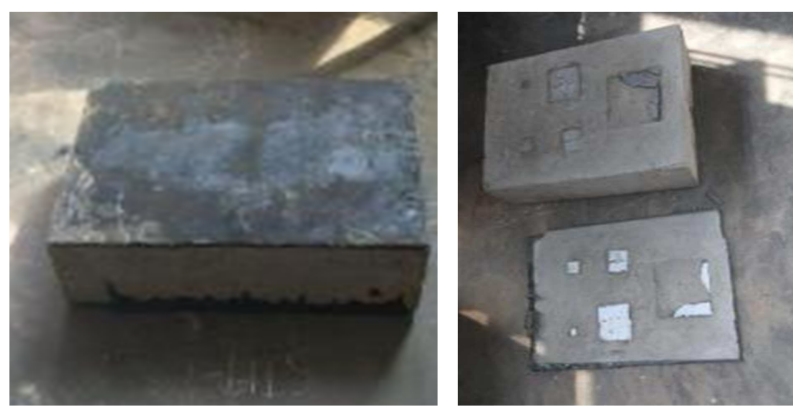

Figure 10. Comparison of complete specimens before and after damaged.

\subsubsection{Vertical Shooting Angle of Infrared Thermal Imager}

Due to space limitations, the vertical thermal infrared imager in this test the shooting angle of $45^{\circ}$ and $30^{\circ}$ angle of depression and head up $\left(0^{\circ}\right)$. According to the experimental results, the average temperature of the surface of the sample is three times of the same temperature. By comparison of temperature, the surface temperature distribution of inner defects in the same time is the same, and the surface temperature decreases with the increase of the angle. In actual engineering, the influence of the vertical angle of the infrared thermal imager on the inner defects of the inner defects in the $45^{\circ}$ range is small.

\subsubsection{Infrared Emissivity}

The emissivity is the ratio of the energy of the body to the radiation of the body surface and the energy of the body at the same temperature. The surface temperature variation of the same sample with the same temperature and the surface temperature of the sample is different. By the graph, the surface temperature increases with the decrease of the emission rate, and the surface temperature at the center of the defect increases with the increase of the speed of the other position. Therefore, in the actual engineering detection, it can be based on the nature of the finish layer material to choose the right infrared thermal imager emissivity.

\subsubsection{The Comparison of Test Results}

The sticking steel concrete parts in the use of infrared thermography detection, the percussion method and the local damage approach to judge the hollowing finishes parts were carried out to confirm the detection. The results show that the infrared thermography detection result is correct. To further verify the feasibility of the experimental results, after the test was carried out to observe the damage, found that the defect position and the actual location of the defects are basically consistent, and the test pieces are shown in Figure 10.

\section{Conclusion}

At present, although there have been many studies on the infrared thermal imaging technology, there are great progress in engineering application, but overall speaking, it still need to be improved in many aspects, the infrared thermal imaging method to detect and paste steel plate reinforced concrete quality test research can provide reference for the relevant research and practical engineering application. In this paper, the normal construction process of the 12 groups of 2 interface in the presence of debonding of concrete sticky steel reinforcement members, application of infrared thermal imaging testing technology for the 2 groups of test pieces of non-destructive-testing, and the main influencing factors were compared with the experimental study, the main conclusions are as follows:

(1) it is feasible to detect the quality of concrete structure by infrared thermal imaging method. The method can check the reinforcement of concrete structure surface quality rapid, non-contact, large area scanning, more hollowing layer thicker, hollowing the position range is easier to tell;

(2) the surface temperature increases with the decrease of the vertical angle and the emissivity of the infrared thermal imager, but the effect of the vertical angle of the infrared thermal imager on the detection results can be neglected;

(3) the accuracy of the infrared thermal imager is greatly influenced by the external conditions, so it is suitable 
to choose the appropriate time and the suitable environment condition. Therefore, it is needed to study the influence factors and the method to reduce the influence of the thermal imager. At the same time, other methods (such as tapping method) were used to test the results of infrared thermal imaging method.

\section{References}

[1] Datcu S, Ibos L, Candau Y, et al. Improvement of building wall surface temperature measurements by infrared thermography. Infrared Physics \& Technology, 2005, 46(6): 451-467.

[2] Youcef M H A L, Mazioud A, Bremond P, et al. A nondestructive method for diagnostic of insulated building walls using infrared thermography//Proceedings of the SPIE, 2007.

[3] Titman D J. Applications of thermography in non-destructive testing of structures. NDT\&E Intertnational, 2001, 34(2): 149-154.

[4] Edis E, Flores-Colen I, Brito J. Passive thermographic inspection of adhered cera mic claddings: Iimitation and conditioning factors. Journal of Performance of Constr ucted Facilities, 2012, 27 (6): 737-747.

[5] ZhuBin, Shen Shaijun. Inspection on adhesion defect of external-wall coating brick with infrared thermography technology Construction Technology, 2009, 38 (S1): 449-151.

[6] AM Birk, MarkH Cunningham. Thermographic Inspection of Rail-Car Thermal Insulation. Transactions of ASME, 2000, 122(11): $494-501$.

[7] Maldague X P V. Theory and practice oI infrared technology for nondestructive testing. A Wiley Inter science Publication, 2001: 495.

[8] Takahide Sakagami, ShiroKubo. Development of a New Non-destructive Testing Technique for Quantitative Evaluations of Delamination Defects in Concrete Structures Based on Phase Delay Measurement Using Lock-in Thermography. Infrared Physics \& Technology, 2002, 43: 311-316.
[9] Sakagami T, Izumi Y, Kubo S. Application of infrared thermography to structural integrity evaluation of steel bridges. Journal of Modern Optics, 2010, 57 (18): 1738-1746.

[10] Uhosh K K, Karbhari V M. Use of infrared thermography for quantitative non-destructive evaluation in FRP strengthened bridge systems. Materials and Structures, 2011, 44(1): graphy of cladding debond in solid rockets. Journal of Mechanical Engineering, 2011, 47(2): 9-15.

[11] Feng Liqiang, Wang Huanxiang, Yan Dawei et al. Experimental study on internal defects detection of exterior wallfinish coat by infrared thermography. Journal of Civil Engineering, 2014, 47(6): 51-56.

[12] Huang Pei, Xie Huicai, Yuan Xin. Concrete bonded steel reinforcement method of infrared thermal image quality. Laser \& infrared, 2004. 34 (5): 50-353.

[13] Huang Wenhao et al. New method of testing the quality of steel bonded reinforcement structure steel sheets. Construction technology, 2006. 37 (6): 465-467.

[14] Li Xiaogang, $\mathrm{Fu}$ Dongmei. Infrared thermal-imaging diagnostic technique. Beijing: China Electric Power Press2006.

[15] JG/T 269-2010 Building infrared thermography detection requirements. Bei jing: Standards Press of China, 2010.

[16] Sun Li, Huan Kewei. The effect of distance on temperature measurement accuracy of the infrared thermal image instrument and correction method. Journal of Changchun University of Science and Technology, 2008, 25 (3): 33-35.

[17] Wang Kai Yan Bogang Zhang Xiyuan et al. Infrared thermograph nondestructive evaluation technique and its application in construction engineering. Concrete, 2015, 5: 154-160.

[18] Li Jiawei, Chen Jimao. Nondestructive testing handbook. Beijing: China Machine PRESS, 2002.

[19] Wu Jiaye, An Xuehui, Tian Beiping. The status and progress of Concrete nondestructive detection technology. Sichuan University of Science \& Engineering (natural sicence edition), 2009, 22 (4): 4-7. 